\title{
GESTÃO EDUCACIONAL E TRABALHO DOCENTE: ASPECTOS SOCIOINSTITUCIONAIS E PSICOSSOCIAIS DOS PROCESSOS DE SAÙDE- DOENÇA
}

\author{
Eduardo Pinto e Silva ${ }^{\mathrm{i}}$ \\ Universidade Federal de São Carlos - UFSCar \\ dups@ig.com.br

\section{Roberto Heloani ${ }^{\mathrm{ii}}$ \\ Universidade Estadual de Campinas - UNICAMP}

\begin{abstract}
RESUMO:
Abordam-se as relações entre gestão educacional e trabalho docente, enfatizando os aspectos socioinstitucionais e psicossociais dos processos de saúde-doença. Relacionam-se os processos de exploração, precarização e intensificação do trabalho do professor à acumulação flexível e ao Estado-gestor. Discutem-se dados de pesquisa em sete instituições federais de Ensino Superior que são contrapostos aos dados de pesquisa em escola estadual de Niterói. Argumenta-se que as políticas e práticas educacionais da Educação Superior influenciam as políticas e práticas da Educação Básica. Aponta-se para o predomínio da sociabilidade produtiva sobre a formação humana e para um modelo de gestão organizacional heterônomo, pragmático e mercantil. Apresentam-se considerações de estudos sobre as relações entre trabalho docente e processos de saúde-doença e reflexões dos conceitos de não-reconhecimento no trabalho e identidade. Conclui-se que as conseqüências prejudiciais à vida sociofamiliar e à saúde do professor se relacionam aos aspectos socioinstitucionais (gestão educacional heterônoma; precarização e intensificação do trabalho) e psicossociais (não-reconhecimento no trabalho; conflitos identitários; competitividade nas relações).
\end{abstract}

Palavras-chave: Trabalho docente; gestão educacional; aspectos psicossociais.

\section{EDUCATIONAL MANAGEMENT AND TEACHER WORK: SOCIO- INSTITUTIONAL AND PSYCHOSOCIAL ASPECTS OF HEALTH-ILLNESS PROCESSES}

ABSTRACT:

This paper approaches relations between educational management and teacher work, emphasizing socio-institutional and psychosocial aspects of health-illness processes. It relates exploitation processes, precariousness and intensification of teacher work to the flexible accumulation and to the Regulatory State. Research data from seven federal higher education institutions are discussed and contrasted with data from a state school of Niterói. It demonstrates that educational policies and practices in higher education may influence policies and practices of elementary education. Findings reveal the predominance of productive sociability in human formation and a heteronomical, pragmatic and mercantile organizational management model. Relations between teacher work and processes of health-illness, taken from other studies, are presented as well as reflections on concepts like non-recognition at work and identity. It was concluded that consequences which are harmful to the teachers' social-familiar lives are related to socio-institutional aspects (heteronomical educational management, precariousness and intensification of work) and psychosocial aspects (non-recognition at work, identity conflicts and competition in the relationships).

Keywords: Teacher work; educational management; psychosocial aspects. 


\section{Introdução}

Este trabalho visa discutir o tema da gestão educacional relacionando-o à Reforma do Estado e à política educacional, de modo a apontar para implicações preocupantes, tais como a exploração, precarização e intensificação do trabalho; sofrimento psíquico, conflito identitário e/ou adoecimento do professor. A discussão do tema vem sendo objeto de debates e atividades desenvolvidos por docentes e orientandos dos Programas de PósGraduação em Educação da UFSCar e da UNICAMP, respectivamente vinculados ao Grupo de Pesquisa em Economia Política da Educação e Formação Humana (GEPEFH) e à linha de pesquisa Gestão, Saúde e Subjetividade. ${ }^{\text {iii }}$

Inicialmente consideramos dados de duas pesquisas. Uma delas, relativa ao período de 1995-2007, foi realizada por Sguissardi e Silva Júnior (2009) em sete instituições federais de Ensino Superior (IFES) da região Sudeste. Outra, de Fortuna (2000), foi realizada em uma escola da rede pública estadual localizada em Niterói (RJ). Procuramos evidenciar traços comuns a respeito da gestão educacional e de suas implicações, acima referidas. De acordo com as proposições de Sguissardi e Silva Júnior (2009), partimos do pressuposto de que as políticas e práticas da Educação Superior se constituem como principal pólo de irradiação das reformas educacionais e do Estado, de modo a influenciarem significativamente as políticas e práticas da Educação Básica. Os aspectos psicossociais apresentados na análise dos dados da pesquisa de Sguissardi e Silva Júnior (2009) foram por nós destacados. Tais aspectos do trabalho docente se caracterizam como foco de análise da pesquisa de Fortuna (2000). A autora aborda a questão da gestão escolar e subjetividade a partir de uma perspectiva psicossociológica, ancorada no marxismo e na psicanálise.

Partimos do pressuposto de que o contexto histórico da acumulação flexível (HARVEY, 1993) e da mundialização e financeirização do capital (CHESNAIS, 1996) se articula às realidades socioinstitucional e política brasileiras, ou seja, à configuração do Estado-gestor e de políticas educacionais orientadas pelo pragmatismo e valores mercantis (SILVA JÚNIOR, 2005) e, desse modo, condizentes aos interesses do sistema produtivo "pós-fordista" (HELOANI, 2003, p.99; ENRIQUEZ, 1997). Ressalvamos que tais aspectos se fazem presentes mundialmente, dado as orientações planetárias do capitalismo e da sociabilidade produtiva (SGUISSARDI \& SILVA JÚNIOR, 2009; SILVA JÚNIOR \& GONZALEZ, 2001).

A discussão das referidas pesquisas é sucedida por considerações de outros estudos sobre os processos de saúde-doença do professor (LEITE \& SOUZA, 2007) e dos conceitos de real, realidade, reconhecimento/não-reconhecimento no trabalho e identidade.

\section{Gestão educacional}

A gestão educacional não se reduz à gestão escolar, pois inclui a gestão do sistema de ensino. Embora a exigência legal da gestão democrática nas escolas direcione discussões sobre os mecanismos e órgãos colegiados da participação coletiva nas decisões do cotidiano escolar (Conselho de Escola, APM, Grêmio Estudantil, eleições de Diretores), podemos afirmar que a busca por um novo paradigma de gestão, efetivamente democrático, participativo e coletivo, jamais prescindirá da presença de amplos e diversos segmentos sociais na gestão educacional no nível mais amplo do sistema de ensino, isto é, na definição das políticas educacionais (LÜCK, 2007).

Segundo Corrêa e Pimenta (2005) existem zonas de interação e influência entre educação e administração, ou seja, desdobramentos no âmbito escolar de concepções de distintos modelos teóricos administrativos. 
As autoras consideram que o modelo clássico ou funcionalista se baseia nos princípios tayloristas de racionalização dos métodos de trabalho e de maximização da eficiência. Nele os conflitos são vistos como anomalias e reduzidos ao técnico e ao administrativo. A gestão é centralizada e o trabalho intensificado e fragmentado. Tal modelo já foi amplamente criticado em função de sua dimensão alienante e a serviço do capital (HELOANI, 2003).

O modelo da Escola de Relações Humanas promove o ajustamento-controle do trabalhador não pela via da coerção, mas da proposição da "participação" em um universo definido pela gerência e pelo "reconhecimento" das necessidades motivacionais. Nele as relações de poder são internalizadas e o conflito é visto como desajuste individual, de forma a se reduzir o político ao psicológico.

No modelo do funcionalismo estrutural as organizações são vistas como estruturas estáveis e com tendência ao equilíbrio ou consenso. Postula-se uma funcionalidade dinâmica e os conflitos são compreendidos como disfuncionais e/ou restauradores do equilíbrio.

Já o modelo do Poder e política se diferencia dos anteriores, pois critica as estruturas de dominação e relaciona os conflitos às questões do poder e da política. Criticase o poder burocrático e o controle exercido pelos especialistas e peritos.

Consideramos que os três primeiros modelos ainda se fazem presentes na gestão educacional e concordamos com as proposições de Corrêa e Pimenta (2005) e de Heloani (2003) que apontam que no pós-fordismo se busca construir modelos organizacionais supostamente baseados no conhecimento e competência. Novos controles, sofisticados, visam produzir a adesão dos sujeitos aos objetivos organizacionais, sob o aparente reconhecimento da subjetividade (ENRIQUEZ, 1997). Tal paradigma, pretensamente novo, tende a configurar uma modalidade de administração escolar que, impactada pela ideologia da qualidade total e das "equipes auto-gerenciadas", reproduz a ordem social vigente e a racionalidade instrumental.

Não obstante, no cotidiano há tensões e não somente a unidirecionalidade de tal racionalidade, o que significa dizer que formas "colegiadas" de "dirigismo" e a atuação do gestor como modelador da cultura organizacional podem e são contrapostas por ações coletivas que delas não se tornam reféns.

\section{A Reforma do Estado e as políticas educacionais}

O pragmatismo é tão antigo como o é a prática educacional. Na esfera da política ele se consubstancializa no Estado-gestor, no hiperpresidencialismo e na anomia da esquerda brasileira, ou ainda, no sistema de macrogestão econômica do capitalismo universalizado (SGUISSARDI \& SILVA JÚNIOR, 2009; FIORI, 1995; SILVA JÚNIOR \& SILVA, 2008).

O pragmatismo também se expressa na esfera da teoria e prática pedagógicas. Duarte (2001; 2000) e Ramos (2001) criticam a pedagogia das competências, o lema "aprender a aprender" e as apropriações (cognitivistas e neoliberais) da obra de Vygotsky, uma vez que se relacionam às práticas educacionais adaptadas à lógica do Estado-gestor $\mathrm{e}$ do sistema produtivo.

Consideramos que, no contexto de hegemonia do pragmatismo tecnológicocientífico, verifica-se progressivamente a submissão das pautas de pesquisas ao mercado e ao sistema produtivo. A articulação entre a Ciência e Tecnologia e a subsunção do saber à lógica mercantil e à macrogestão econômica, ainda que não se caracterize como totalizante, pode ser compreendida como predominante (SGUISSARDI \& SILVA JÚNIOR, 2009; SILVA JÚNIOR \& SILVA, 2008). 
A política educacional submete-se à política fiscal do Estado mínimo e à macrogestão da economia. $\mathrm{O}$ aumento de práticas educacionais rentáveis inscreve-se no interior da lógica de minimização de custos e de maximização da eficiência. Assim, no atual contexto educacional, mediado pela Reforma do Estado e pelas proposições de políticas educacionais mercantis que valorizam o conhecimento prático e útil, há uma acentuação do pragmatismo, notadamente através da produção de valor do trabalho imaterial (SGUISSARDI \& SILVA JÚNIOR, 2009).

\section{Da Educação Superior à Educação Básica: precarização e intensificação do trabalho}

Sguissardi e Silva Júnior (2009) partem da proposição teórica do papel central do conhecimento nas atuais formas de reprodução e valorização do capital e analisam a política educacional e o que denominam gestão heterônoma de sete IFES da região Sudeste.

Segundo Sguissardi e Silva Júnior (2009) a CAPES, responsável pela reorganização da pós-graduação no Brasil, induz docentes à pesquisa aplicada e articula-se ao CNPq que, por meio de editais, convênios e fundos de natureza variada, possibilita que o mercado se ponha dentro da universidade e a universidade se ponha no mercado.

No trânsito entre pesquisadores e o setor produtivo se concretiza a superficialidade extensiva e a simbiose entre utilidade e pragmatismo. $\mathrm{O}$ produtivismo acadêmico, compreendido como ideologia produzida pela burocracia da CAPES e do CNPq, é naturalizado e reproduzido nos espaços institucionais da universidade "quase mercantilizada" (SGUISSARDI \& SILVA JÚNIOR, 2009, p.130). Professores tendem a internalizar como natural a intensificação e precarização do trabalho. Assim, são produzidas conseqüências negativas para a sua vida sociofamiliar, identidade pessoal/profissional e saúde, dentre as quais se destacam: a indissociação do tempo e espaço pessoais e de trabalho; estresse, individualismo e competitividade no trabalho (SGUISSARDI \& SILVA JÚNIOR, p.138-146; p.148-155; p.192-199, 2009).

No âmbito da pós-graduação e da educação, de modo geral, verifica-se uma sobrevalorização de indicadores e resultados supostamente quantificáveis e mensuráveis. O conceito de accountability se relaciona a tal sobrevalorização e revela a penetração de mecanismos de mercado no espaço público estatal e educacional. Não obstante, a gestão educacional heterônoma, ainda que predominante, é contraposta por outras práticas. $\mathrm{Na}$ "reconfiguração organizacional e identitária" das IFES, verificam-se práticas reprodutoras $e$ reatoras às orientações, determinações ou imposições da Reforma do Estado (SGUISSARDI E SILVA JÚNIOR, p.5, 2009).

Sguissardi e Silva Júnior (p.42-100, 2009) apresentam dados contundentes a respeito da precarização e intensificação do trabalho no período de 1995-2005: aumento de $50,1 \%$ das matrículas das IES públicas; crescimento de $36 \%$ da relação professor aluno; redução de $-32 \%$ de funcionários técnico-administrativos; descompasso entre aumento de cursos e evolução do corpo docente, sendo que no caso de uma delas houve crescimento de $400 \%$ dos cursos de doutorado e evolução de $17 \%$ do corpo docente; redução de $-62 \%$ de recursos próprios das IFES da amostra; redução de $-30 \%$ de recursos totais de todas as fontes destinados para as IFES da amostra; redução de $-34 \%$ de recursos (excluídos os próprios) destinados ao pagamento de pessoal e encargos; redução de $-80 \%$ de recursos federais para investimentos nas IFES; redução do poder aquisitivo do salário dos professores de $-20,14 \%$ (Adjunto IV) e $-21,19 \%$ (Titular); frequentes contratações de professores substitutos, exército de reserva para suprir as vagas produzidas e não preenchidas à sombra das políticas oficiais para as IFES nos últimos 10 a 15 anos. 
Os dados indicam basicamente o seguinte: a política educacional caracteriza-se como de expansão limitada do subsistema, tendo sido levada a cabo com o máximo de redução de custos e de forma afinada à Reforma do Estado e à reestruturação produtiva.

Assim, tende a se consolidar uma "heterogestão institucional" condizente à simbiose Estado-Universidade-Mercado-Sistema Produtivo, mediada pelo CNPq e CAPES. A reforma da universidade dá o tom às políticas e práticas da Educação Básica e pode ser apontada como pólo irradiador da Reforma do Estado (SGUISSARDI \& SILVA JÚNIOR, p.9-41, 2009).

\section{a) Aspectos psicossociais do trabalho do professor-pesquisador}

No que tange aos aspectos psicossociais, destacamos a fala de uma professora de uma das IFES seduzida pelo ardil do produtivismo acadêmico: "Acho que eu tenho uma paixão que eu não consigo explicar. Eu realmente não tenho resposta. Eu vejo que sou explorada, mas eu compactuo com essa exploração" (SGUISSARDI \& SILVA JÚNIOR, p.189, 2009). Tal depoimento nos remete à análise de Pagès (1987) sobre a dominação em uma multinacional, na qual se aponta que há um empobrecimento da identidade do trabalhador e sua adesão ao ideal de ego organizacional em substituição ao seu próprio ideal de ego.

Sguissardi \& Silva Júnior (2009) consideram que os professores aderem e acentuam, na prática universitária, a sociabilidade produtiva. Alguns se aprisionam aos seus desejos e necessidades narcísicas, aos símbolos de prestígio e poder. "Apaixonam-se" pela imagem de si enaltecida/auto-enaltecida. Submetem-se a um cotidiano estressante/competitivo e até mesmo às "férias no papel" (SGUISSARDI \& SILVA JÚNIOR, p.139-141, 2009). Os autores abordam a existência de uma indissociação do tempo e espaço pessoais e de trabalho, relacionando-a ao estresse (SGUISSARDI \& SILVA JÚNIOR, 2009).

Aponta-se para o individualismo, competitividade no trabalho e deterioração das relações laborais. Professores convivem com o que foi referido como "coisa massacrante" e "sarrafos da CAPES", numa ambivalente mescla de desgaste e (pseudo) "autosatisfação” (SGUISSARDI \& SILVA JÚNIOR, p.139-141, 2009).

A gestão heterônoma do prazer-angústia produz uma "paixão" não explicável, abordada por Sguissardi e Silva Júnior (2009) e Silva Júnior e Silva (2008) a partir da metáfora da droga, ou seja, da substância que passa a fazer parte de si, que dá prazer e gera angústia e com a qual se cria uma relação de dependência.

Um dos depoentes menciona haver um "sequiestro da subjetividade": "acho que hoje a universidade seqüestra dos professores a subjetividade [...] O tempo inteiro ela está te sugando e usando controles sutis e sofisticados". Outros fazem referência aos termos "massacre" e "estresse": "estresse [...] pressão enorme pra publicação"; "uma coisa massacrante [...] mas o pessoal ainda suporta bem os sarrafos da Capes" (SGUISSARDI \& SILVA JÚNIOR, p.154; p.138-139, 2009).

\section{b) Aspectos psicossociais do trabalho do professor da rede pública estadual}

Os dados sobre salários, contratação de professores substitutos e más condições de infraestrutura de trabalho na rede pública são bastante conhecidos e também referidos por Fortuna (2000). 
Consideramos que a questão da heteronomia da gestão também se faz presente, tanto nas formas como as escolas são avaliadas como nos mecanismos de gestão financeira, mais condizentes à noção de desconcentração do que à de descentralização (LÜCK, 2007). No que tange à gestão financeira o pragmatismo mercantil se faz presente. São incentivadas as parcerias público-privadas e o empreendedorismo por um paradigma "participativo" que deixa muito a desejar (LÜCK, 2007).

Alguns aspectos relacionados à subjetividade do professor da rede pública são bastante distintos daqueles do professor-pesquisador. O trabalho intenso, o estresse e a redução do tempo disponível para o lazer e família são acompanhados por aspectos subjetivos diametralmente opostos aos do orgulho, prestígio e poder dos professorespesquisadores.

Fortuna (2000) aponta que existem laços libidinais no grupo de professores da escola por ela pesquisada. Demonstra que a democracia é de caráter tutelar e que existem contradições entre o discurso e a prática da gestão. A realidade escolar se caracteriza por uma cultura da acomodação, na qual a dimensão inventiva e criadora do coletivo tende a se esgotar. O grupo de professores tende a se estruturar em torno de um fantasma da dependência e geralmente personifica o ideal da gestão democrática na figura do Diretor que assume a condição de "egocrata": "nem déspota, nem tirano, encontra no seu eu a lei de todas as coisas” (FORTUNA, 2000, p.114, p.119-139).

Desse modo, não se estrutura uma gestão coletiva. O grupo apresenta uma modalidade de investimento psíquico na relação entre dirigente e dirigido que se configura como doublé de uma relação parental. Os "dirigidos" vivenciam o arquétipo do órfão e o medo do abandono e da exploração. Tendem a se comportar passivamente, como que a espera da salvação por outrem. Tais aspectos ao mesmo tempo ambivalentes e fantasiosos das relações de trabalho mesclam-se a outros, objetivos: o descaso do Estado, a exploração do trabalho mediante baixa remuneração, a falta de investimento nos desenvolvimentos profissional e institucional. Os "dirigentes", por sua vez, encarnam o arquétipo do guerreiro, assumindo a missão messiânica de "salvar a escola". As relações ambivalentes estruturadas dificultam a filiação dos atores educacionais a uma ordem simbólica e a um ideal mobilizador da imaginação criativa. Prevalece o que Enriquez (1997) denomina imaginário enganador, ou seja, o ideal meramente ilusório.

O modelo tecnocrático e a gestão heterônoma das práticas educacionais, a reboque das políticas da Educação Superior e da configuração do Estado-gestor, podem ser relacionados à condensação de diferentes temporalidades históricas que se concretizam na cultura e cotidiano da realidade escolar (SILVA JÚNIOR \& FERRETTI, 2004) que, segundo Fortuna (2000), mesclava autoritarismo, paternalismo, clientelismo e corporativismo.

Assim, a autora demonstra a existência de traços indentificatórios que não propiciavam relações de trabalho sublimatórias, mas sim patogênicas (DEJOURS, 1994). Tal como na realidade da prática universitária, mas por caminhos específicos e sob dimensões subjetivas distintas, se desmobiliza o potencial do processo coletivo de ação. Nesse sentido, as relações intersubjetivas entre professores e professores e Direção são compreendidas como sintomas de uma realidade escolar marcada por uma realidade política e socioinstitucional coisificante e que tende a sufocar o desejo ou pulsão subjetiva. Tal nos remete, portanto, ao "seqüestro da subjetividade", referido por um dos professorespesquisadores.

Tais aspectos psicossociais do trabalho do professor acima apontados demandam a discussão dos processos de saúde-doença e para sua relação com o não-reconhecimento no trabalho e conflitos identitários. 


\section{Trabalho e processos de saúde-doença}

Os estudos que buscam relacionar o trabalho com os processos de saúde/doença possuem já uma longa história, seja no campo das teorias organizacionais, seja na área da saúde em suas distintas dimensões. Aliás, Karl Marx dá um exemplo interessante de recrutamento em massa de crianças, praticado em Londres no ano de 1866, catorze anos antes de Frederick Taylor iniciar o seu trabalho.

[...] Em Bethnal Green, distrito mal-afamado de Londres, todas as manhãs de segunda e terça-feira realiza-se publicamente leilão, e crianças de ambos os sexos, a partir de 9 anos, se alugam diretamente às fábricas de seda de Londres. Os contratos são válidos apenas por uma semana. As cenas e o linguajar desse mercado são realmente revoltantes. [...] Apesar da legislação, 2.000 garotos pelo menos são vendidos pelos pais, na GrãBretanha, como máquinas vivas de limpar chaminés, embora existam máquinas para substituí-los. (MARX, 1971, pp. 452-453).

Como se vê, insalubridade no local de trabalho, alienação do trabalhador e de seus familiares, extensas jornadas laborais e um exército industrial de reserva - às vezes constituído por crianças - são objeto de análise e discussão desde longa data. Mas foi na década de 1960, com a significativa intensificação do trabalho gerada pelo taylorismofordismo, que o assunto "saúde mental e trabalho" (SM\&T) ganhou dimensões semelhantes ao do movimento que lhe deu guarida, ou seja, o movimento estudantil/operário de maio de 68, embora um movimento denominado Psiquiatria Social já existisse desde meados da década de 1940. Nas múltiplas manifestações do ano de 1968, que questionaram conceitos presentes na sociedade moderna em todos os seus âmbitos e atingiram proporções fenomenais, as expressões como "saúde não se vende" ou "saúde não tem preço" se uniram às do tipo "métro-boulot-dodô" (metrô-trabalho-cama), que reflete a cansativa rotina do trabalhador médio.

É assim que Dejours (1994) adota, de forma explícita, nesta área, ou melhor, na Psicodinâmica do Trabalho, alguns conceitos e categorias da psicanálise. Alguns princípios são recorrentes em seus escritos, tais como: a) aquele que sinaliza que o trabalhador não é um receptor passivo de agentes provocadores de doença, mas participa desse processo desenvolvendo um papel significativo na criação de um sistema defensivo; b) situações de doença e saúde não se opõem, na análise das doenças decorrentes da organização do trabalho (condições de trabalho), pois os limites são tênues e reversíveis; c) na análise destas condições de trabalho o sofrimento físico e psíquico tem importância capital.

A Psicodinâmica do Trabalho vem pesquisando um fenômeno que intrigou Dejours (1992; 1994) a partir de suas pesquisas de campo: a normalidade. Em um primeiro momento, seguindo a tradição da Psicopatologia do Trabalho, entendia as condições de trabalho como uma situação monolítica que se impunha sobre os indivíduos, deixando pouca margem de manobra para a adaptação dos trabalhadores. Apesar destes lançarem mão de estratégias defensivas contra o sofrimento produzido por estas situações, a idéia era a de que seria quase que impossível afastar os riscos da afecção psicopatológica. O que os resultados de pesquisa e intervenção mostraram, porém, foram situações onde os indivíduos continuavam a agir "como se nada estivesse ocorrendo". As defesas de alguma forma evitavam o adoecimento, ainda que o sofrimento psíquico se fizesse presente.

Apontaríamos como exemplos do sofrimento do trabalho em empresas hoje: irritação; angústia ante as pressões do trabalho; insatisfação de todas as ordens devido a certas condições de trabalho; cefaléias; insônia; obesidade; alergias; quedas de cabelo etc. 
Nas escolas, o burnout talvez seja a "patologia" (síndrome) que melhor expressa a situação de sofrimento psíquico no trabalho, tal como se aponta em estudo recente sobre o estado da arte da produção acadêmica sobre as relações entre condições de trabalho e adoecimento do professor (LEITE \& SOUZA, 2007).

Dejours $(1992 ; 1993 ; 1994 ; 1997)$ se pergunta por que muitas vezes os trabalhadores não adoecem de fato. Em muitos casos o autor percebe que o equilíbrio conseguido era instável: os indivíduos opunham uma enorme força contra as pressões organizacionais desestabilizadoras, cujo resultado era o de estarem sempre em equilíbrio precário. Mas, o que o Dejours (1992) também observa é que este estado de normalidade implicava equilíbrio saudável. Logo, a normalidade é um fenômeno complexo e passou a ser objeto de pesquisa e preocupação por parte deste pesquisador. Neste momento é que, para abarcar novos fenômenos, Dejours (1994) passa a denominar sua atividade de Psicodinâmica do Trabalho ou Análise Psicodinâmica do Trabalho.

Para o desenvolvimento da Psicodinâmica do Trabalho foi então essencial abandonar a idéia de um real monolítico, que não podia ser alterado para o trabalhador poder melhor se adequar à sua atividade de trabalho, em relação à qual lhe restava tão somente adaptar-se. Nesse sentido, Dejours (1994) supera as visões do trabalho como fonte exclusiva de sofrimento patogênico e das defesas como estratégias que dificilmente poderiam evitar e/ou afastar os perigos do adoecimento psíquico. Passa a melhor observar a dimensão sublimatória do trabalho e as estratégias defensivas que permitem a renormatização do trabalho prescrito, ou seja, as saídas distintas da do adoecimento.

Assim, como as pesquisas posteriores de Dejours (1994) nem sempre comprovavam os pressupostos da Psicopatologia do Trabalho, ele os repensou e lançou mão de outras categorias explicativas: normalidade; prazer; trabalho prescrito e trabalho real criativo; realidade diversa do real; tricherie; sublimação; julgamento e reconhecimento do que-fazer; identidade; atos de linguagem/ação comunicativa; espaço público e construção do coletivo do trabalho. Trata-se então de um novo campo epistemológico a ser trabalhado que não nega o anterior, mas o problematiza e ultrapassa-o, no sentido de ressignificar o próprio conceito de patogênico e não-patogênico. Infelizmente, fugiria de nosso objetivo discutir aprofundadamente tal questão.

O levantamento do estado da arte de estudos acadêmicos relativos às relações entre condições de trabalho e processos de saúde-doença de professores, realizado por Leite e Souza (2007, p.7), nos revela que, de modo geral, "há uma predominância de estudos sobre saúde mental: estresse, burnout, mal estar, entre outros, construídos a partir do campo de conhecimento da psicologia e biologia". As autoras também destacam os estudos influenciados pela abordagem ergonômica, que apontam para o "trabalho repetitivo, fragmentado em tarefas e submetido a intensos ritmos de trabalho", assim como para estudos fonoaudiológicos, que demonstram haver uma correlação entre disfonia e estresse (LEITE \& SOUZA, 2007, p.7; p.76).

O campo da Psicologia envolve contribuições variadas, com distintos enfoques e bases epistemológicas. As autoras apontam que há influências da visão médico-biológica da área de saúde que não aprofundam as relações entre adoecimento do professor e questões sociais, institucionais e da organização e gestão do trabalho.

Os estudos de Dejours (1994), Esteve (1999) e Codo (1999) são apontados como importantes marcos teóricos pelas autoras no sentido de uma visão mais abrangente (LEITE \& SOUZA, 2007). 
Como se apontou acima, a perspectiva de Dejours $(1992 ; 1993 ; 1994 ; 1997)$ enfatiza as relações entre adoecimento, sofrimento psíquico e as defesas dos trabalhadores frente os processos patogênicos de gestão e organização do trabalho. Quanto menor a autonomia no trabalho e mais rígida as suas prescrições, o modo operatório da realização da tarefa assim também se caracteriza, de forma que o trabalho tende a se configurar como patogênico. Voltaremos a tais considerações adiante, enfatizando o não-reconhecimento no trabalho e os aspectos indentitários conflitivos.

Esteve (1999) cunhou o termo "mal-estar docente", que ele reconhece como intencionalmente ambíguo, justificando-o pelo fato de que nós saberíamos que algo não vai bem, mas temos dificuldades de definir o que não "funciona" e por quê. Não obstante, relaciona o mal-estar docente aos seguintes aspectos: desvalorização do professor; constantes exigências profissionais; violência e indisciplina. Tais aspectos promoveriam uma crise de identidade. Assim, aponta para sentimentos negativos intensos, angústia, alienação, ansiedade, exaustão emocional, frieza diante das dificuldades de outros, insensibilidade e postura desumanizada. Tratam-se de indicadores do que se conceituou como burnout.

Codo (1999), que trilhou os caminhos abertos por Dejours (1994) e Esteve (1999), ainda que com críticas e algumas ressalvas a ambos, contribuiu significativamente para a compreensão e difusão da discussão do burnout docente no Brasil a partir de pesquisa nacional. Apresenta como principais indicadores do burnout a exaustão emocional, a despersonalização e a não-realização com/no trabalho. A sintomatologia física e psíquica do burnout é similar à do estresse. Destacamos alguns aspectos comportamentais e defensivos, tais como o cinismo, o desencantamento com o trabalho, a ironia e/ou agressividade, o sentimento de impotência mascarado por mecanismo defensivo (sentimento de onipotência) e a tendência ao isolamento.

O estudo de Codo (1999) consiste em uma ampla análise sobre as condições de trabalho e saúde mental na educação brasileira, com o mérito de articular Educação, Psicologia, Economia e Sociologia do Trabalho. Foram abordados 52 mil profissionais de escolas públicas estaduais do país. Aponta-se que se trata de atividade profissional mediada pelas tensões entre afeto e razão. O circuito afetivo é muitas vezes compreendido como interceptado, sendo que a racionalidade burocrática é apontada como fator causal de considerável peso, ainda que haja uma multicausualidade etiológica.

Codo (1999) também se refere à crise da identidade apontada por Esteve (1999) e à questão do burnout, cuja concepção pioneira é de Freudenberger (1974; 1975). Para este autor, trabalhadores acometidos pela síndrome de burnout são pessoas exauridas e cansadas de lutar, que geralmente parecem ter perdido enorme energia e que se sentem derrotadas e com possibilidade de agir prejudicada. Do nosso ponto de vista, a partir de tais considerações, compreendemos ser o burnout condição muito próxima da do estresse em fase de exaustão e, vale ressaltar, distinta da do estresse em fase de resistência.

Leite e Souza (2007, p.41) enfatizam também a importância do estudo de Vieira (2004), embora este não tenha tido a divulgação e a centralidade do de Codo (1999). Tratou-se de investigação realizado pela Confederação Nacional dos Trabalhadores da Educação (CNTE) com 4.656 professores, em sua maior parte proveniente de escolas públicas estaduais $(71 \%)$ e municipais $(11 \%)$. O cerne da análise de Vieira (2004) é o da identidade profissional expropriada. Segundo tal autora, a identidade do professor tende a ser ameaçada, violentada e cindida pelas precárias condições de trabalho, assim como por formas de gestão e organização do trabalho que tendem a dificultar senão impossibilitar a participação e a autonomia docentes. 


\section{O estigma e o não-reconhecimento no trabalho: considerações preliminares}

Gostaríamos de desenvolver, a partir deste momento, o que acontece ao indivíduo quando o julgamento no trabalho lhe é desfavorável e dele não se obtém reconhecimento, tal como infelizmente acontece com boa parte dos professores do ensino fundamental e médio no Brasil. Ele fica sujeito ao sofrimento patogênico, pois o que está em jogo é a fragilização de sua identidade, sendo esta compreendida como fundamental para o fortalecimento psíquico do sujeito e da produção de sua saúde mental. Neste sentido, a sua debilitação pode levar ao adoecimento psíquico.

Segundo Honneth (2003), em seu texto Luta por reconhecimento, a ausência de reconhecimento no âmbito do trabalho é uma questão vital. No nosso entender pode vir a ser tão ou mais patogênico do que a utilização desmesurada de subterfúgios, tais como álcool, drogas, uso inadequado de alimentos etc.

Goffman (1963) permite discutir sob outro ângulo o que pode ocorrer com esse sujeito. Para este autor, identidade social seria o conjunto de atributos que são considerados comuns e que determinam que o indivíduo seja aceito como membro de uma categoria. Assim, formam-se concepções prévias que se transformam em expectativas normativas. Para o mesmo autor, a identidade social virtual se caracteriza por aquilo que esperamos que o indivíduo seja, enquanto que aquilo que na realidade ele prova ser constituiria a sua identidade social real. Assim sendo, o estigma se daria quando viesse a ocorrer "uma discrepância entre a identidade social virtual [aquilo que esperamos que ele seja] e a identidade social real [aquilo que ele realmente é]" (GOFFMAN, 1963, p.12).

Historicamente o termo estigma esteve ligado a sinais corporais que evidenciavam algo de extraordinário, fora do comum, ou mesmo negativo do status de quem o apresentava. Tinha como função sinalizar a pessoa para categorizá-lo como criminoso, traidor ou escravo. Hoje é mais aplicado ao infortúnio do que à simples evidência corporal. Nesse sentido, o termo estigma diz respeito a uma suposta característica (maldade, fraqueza, defeito, desvantagem etc) de um indivíduo que o torna diferente de outros que estejam em uma categoria na qual o primeiro possa ser incluído. Deixa de ser considerado um indivíduo comum e é reduzido a uma pessoa estragada e diminuída. Mas adverte Goffman (1963, p.13) que "um atributo que estigmatiza alguém pode confirmar a normalidade de outrem, portanto ele não é, em si mesmo, nem honroso, nem desonroso”. Estigma não deve ser confundido com estereótipo. Entendemos por estereótipo uma série de características como sendo tipicamente de uma pessoa. Nem sempre estas são negativas. Segundo Romero (apud Teixeira, 1994):

Os estereótipos podem ser positivos e negativos, isto é, as características podem ser desejáveis ou não [...] o estereótipo pode ser definido como parte do preconceito, sendo este sempre negativo, e o estereótipo sendo uma idéia preconcebida a respeito de uma pessoa ou um grupo de pessoas, que mantém as características de rigidez, super-simplificação, generalização e falta de informações mais completas [...] simplificam a realidade objetiva. (1994, p.26).

O que acontece com o indivíduo estigmatizado? Goffman (1963, p.18-20) sugere algumas possibilidades tanto do ponto de vista físico como do psicológico. 
Do ponto de vista físico o indivíduo pode usar o seu estigma para ganhos secundários como desculpa pelo infortúnio a que chegou. É o sujeito que se coloca como vítima da desgraça e busca sensibilizar o outro e seduzi-lo a "compensá-lo" de seu problema. O operário que expõe o dedo que perdeu e que pede ajuda financeira procura ganhos secundários como desculpa pela situação de "fracasso" a que chegou. Ele também pode tentar corrigir o problema de forma indireta, dedicando um significativo esforço pessoal ao domínio das áreas consideradas como fechadas (ex: o deficiente físico que busca amenizar o problema e que aprende a nadar). Por fim, pode mesmo tentar corrigir diretamente o problema mediante cirurgia, psicoterapia ou outras intervenções. Ou mesmo, encarar as privações como uma bênção secreta, mormente devido à crença de que o sofrimento muito pode ensinar sobre as pessoas e sobre a própria vida.

Para entendermos como as pessoas se sentem estigmatizadas do ponto de vista psicológico é importante reproduzirmos aqui o que Goffman (1963) diz a respeito de um indivíduo que tivesse consciência de sua suposta inferioridade:

[esta consciência] significa que a pessoa não pode afastar do pensamento a formulação de uma espécie de sentimento crônico do tipo de insegurança que conduz à ansiedade e, talvez algo ainda pior, no caso de se considerar a inveja como realmente pior do que a ansiedade. $\mathrm{O}$ medo de que os outros possam desrespeitá-la por algo que ela exiba significa que ela sempre se sente insegura em seu contato com os outros; essa insegurança surge, não de fontes misteriosas e um tanto desconhecidas como uma grande parte de nossa ansiedade, mas algo que ela não pode determinar. Isso representa uma deficiência quase fatal do sistema do 'eu' na medida em que este não consegue disfarçar ou afastar uma formulação definida que diz 'eu sou inferior, portanto as pessoas não gostarão de mim e eu não poderei sentir-me seguro com ela'.(GOFFMAN, 1963, p.22).

Como se apontou anteriormente, o sentimento de abandono/insegurança e a questão da competitividade ou mesmo agressividade são presentes, respectivamente, nos casos dos professores da Educação Básica e dos professores-pesquisadores.

A partir das considerações de Goffman (1963), podemos postular que uma pessoa sente-se insegura no que concerne à maneira como os ditos "normais" a sinaliza e a recebe. $\mathrm{O}$ sujeito tende a observar que erros insignificantes ou enganos acidentais podem ser interpretados como uma expressão diretamente relacionada ao atributo estigmatizado (GOFFMAN, 1963, p.23-24).

Com isto podemos deduzir que o indivíduo estigmatizado pode responder a uma situação social complexa mediante uma capa defensiva. Ao contrário do que se possa pensar, o indivíduo que sofre estigma pode não se retrair e talvez tente aproximar-se do contato desejado de forma agressiva, provocando uma série de respostas também agressivas e desagradáveis. Assim, essa situação social complexa poderá vir a representar uma interação angustiada, com fortes conseqüências dramatúrgicas. A pessoa estigmatizada percebe o mal-estar na relação e sabe que o outro também o percebe. Inclusive sente que este outro não ignora que ela o percebe. Isto reflete, no nosso entender, o complexo jogo dramatúrgico discutido por Goffman (1963, p.25-27). 
As considerações teóricas acima explicitadas possuem relação de proximidade com a questão do arquétipo do órfão, apontado quando da discussão dos aspectos psicossociais do professor da escola estadual de Niterói, assim como a noção de mal-estar docente de Esteve (1999). A capa defensiva criada diante da situação social complexa, por sua vez, relaciona-se às proposições de Dejours (1994) e aos aspectos dos processos de saúdedoença, sobretudo o burnout (Codo, 1999; Freudenberger, 1974; 1975).

\section{O não-reconhecimento no trabalho e os conflitos identitários}

A "normalidade" aparece como "realidade" tanto para as pessoas envolvidas nas relações organizacionais como para o observador externo. Esta "realidade" é mais abrangente do que a realidade específica do trabalho: para o desenvolvimento da atividade laboral existem prescrições, normas e regras de procedimento de como esta deve ser desenvolvida, ou seja, existe toda uma tradição criada que irá definir como deve ser percebida uma determinada realidade e como se deve agir (tecnicamente) sobre ela (DEJOURS, 1997).

Para Berger e Luckmann (1991, p.228-229) a realidade é constituída socialmente e, portanto, é uma qualidade pertencente a fenômenos que reconhecemos existirem independentemente de nossa visão. Esses autores tentam demonstrar que a "realidade", especialmente da vida cotidiana, é vivida por nós de maneira cristalizada, urgente e intensa e que se impõe à nossa consciência deste modo. Assim poder-se-ia dizer que tal "realidade" - que já existia antes de nós, pois é ordenada em padrões e é previamente disposta, aparece já objetivada.

Esta é a "realidade" que um indivíduo encontra quando entra em uma determinada organização do trabalho. Ela está dada e vai se impondo, tanto no que diz respeito às relações organizacionais como um todo, como em relação aos procedimentos da atividade que vai desenvolver.

Observando-se a inserção deste indivíduo em uma área específica da organização do trabalho, este sujeito vai deparar-se com o real do trabalho. Este último elemento surge como resistência aos ditames: são situações inéditas, desconhecidas e imprevistas que desafiam as indicações. Dada a pressão organizacional, o trabalhador se vê num dilema: para trabalhar deve transgredir, caso contrário fica paralisado, o que também não pode ocorrer. Invariavelmente o indivíduo lança mão de "trapaças", "jeitinhos" ou "gambiarras"

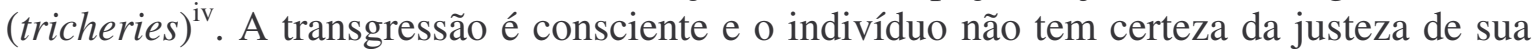
solução. Para superar esta angústia vai se submeter ao julgamento do outro, a fim de poder avaliar a solução dada a um problema.

Dejours (1993) coloca que existem dois tipos de julgamento:

Julgamento de utilidade: [...] é um julgamento que diz respeito à utilidade social, econômica ou técnica do trabalho feito pelo sujeito sobre o campo de atividade. Este julgamento, essencial e incontornável, é antes de tudo formulado pelos superiores hierárquicos e pela chefia, que são as pessoas melhor situadas para apreciarem a utilidade do trabalho efetuado, e, eventualmente, pelos clientes, ou seja, segundo as relações no sentido vertical." (DEJOURS, 1993, p.148). 


\begin{abstract}
Julgamento estético: "[...] o julgamento de beleza se decompõe em dois desdobramentos: o julgamento em virtude do qual o trabalho é reconhecido como apresentando todas as qualidades que implicam o respeito às regras de trabalho ou às regras de arte [...]. Em outros termos, o julgamento de beleza é formulado [...] pelos pares. É um julgamento muito mais severo, muito mais exigente. [...] Este julgamento de beleza, socialmente formulado, não é pois evidente em si mesmo [...] É preciso que cada um obtenha de seus pares esse julgamento. Em outras palavras, a sublimação só é cumprida quando o julgamento for obtido pelo impetrante [...] Quando este julgamento é proferido pelos pares, ele dá, em contrapartida da contribuição do sujeito à obra comum, uma retribuição em termos de identidade. Com este primeiro julgamento de beleza, o sujeito é reconhecido como possuidor de todas as qualidades e das habilidades daqueles que formam o coletivo do trabalho, a equipe, ou, na falta dela, a comunidade a que pertence [...]. Esse primeiro desdobramento do julgamento de beleza é necessário para que se tenha sucesso no segundo desdobramento: trata-se, desta vez, além das qualidades comuns, de reconhecer o que faz essencialmente a diferença em relação aos outros. Desta vez, é a originalidade que é reconhecida, mas com a condição de que de início sejam respeitadas as regras comuns.. Este julgamento é, para nos exprimirmos com precisão, aquele pelo qual é reconhecida a identidade, isto é, aquele pelo qual esse sujeito não existe em nenhum outro semelhante a ele.(DEJOURS, 1993, p.148149).
\end{abstract}

Caso isto ocorra, Dejours (1993) coloca que vai haver o fortalecimento da identidade do sujeito. Nesse sentido haverá crescimento e maturação do indivíduo. Por outro lado, quando o julgamento for desfavorável, este não poderá usufruir do reconhecimento e no limite poderá ser estigmatizado, no sentido que Goffman (1963) empresta a este conceito.

Nos casos considerados na introdução, podemos considerar que há um bloqueio do julgamento de utilidade em função de uma gestão de caráter heterônomo. No caso do professor-pesquisador, seu trabalho tende a ser reconhecido somente quando útil ao sistema produtivo e/ou quando propicia a captação de recursos externos aos da universidade, ou seja, quando se caracteriza por pesquisa aplicada. No caso do professor da rede estadual da Educação Básica, podemos afirmar que o julgamento tende a ficar à mercê da Direção egocrata.

Já no que diz respeito ao julgamento estético, podemos considerar que este também se encontra com sérios impedimentos, em função de relações de trabalho permeadas por individualismo e competitividade, senão cinismo e agressividade. Não obstante, nos parece mais viável de ocorrer do que o julgamento de utilidade, sobretudo quando tais aspectos das relações de trabalho são mais amenos, menos corriqueiros ou mesmo ausentes.

$\mathrm{Na}$ atividade docente, cada vez mais o não-reconhecimento se torna a regra e a identidade profissional se torna deteriorada, com o concurso de parcela significativa da mídia. Esta, não raro, constrói no imaginário popular uma imagem docente burlesca, caricata, tão fácil de ser localizada em programas humorísticos. Some-se a isso, um parco salário que, numa sociedade com valores forjados na lógica capitalista, se apresenta como aviltante.

Retomando a questão do reconhecimento estético (ou de beleza), Dejours (1993) articula-os ao fortalecimento da identidade. Para compreender tal questão, o autor aponta que é fundamental, antes de mais nada, distinguir identidade de personalidade: 
[...] uma parte importante da tradição psicanalítica confere um lugar essencial à análise da personalidade ou do caráter, isto é, às invariantes que resultam da sedimentação do drama da infância e conferem à pessoa uma estabilidade que freqüentemente foi caracterizado como uma estrutura. Portanto, a personalidade, o caráter ou a estrutura não afastam os riscos da crise psíquica e da descompensação. $\mathrm{O}$ recurso à noção de identidade permite justamente problematizar esta tensão entre o que vem do passado que confere a estabilidade e o que na atualidade, cria o risco de desestabilizar o sujeito ou de provocar as crises de mudança. A identidade nesta perspectiva conserva sempre uma certa precariedade e jamais é definitivamente adquirida. (DEJOURS, 1993, p.189).

A identidade implica para o autor aquilo que torna o indivíduo único, singular, diferente dos outros. É construída na relação com o outro, no processo de alteridade. O julgamento, neste sentido, é capital, e diz respeito ao trabalho e não ao sujeito, ao fazer e não ao ser. $\mathrm{O}$ fazer, por sua vez, se relaciona à possessão do saber-fazer e do conhecimento do métier e de suas regras por parte do sujeito.

Sendo assim, podemos afirmar que o julgamento sinaliza, somente em um segundo momento, para o reconhecimento do ser. Na sublimação, pelo que sugere a clínica em psicodinâmica do trabalho, o reconhecimento da identidade passa pela mediação do trabalho. Ela jamais é direta. A cada vez que nessa etapa intermediária for gerada uma espécie de curto circuito, toda a economia da sublimação será arruinada.

$\mathrm{Se}$ o reconhecimento dissesse respeito diretamente ao ser, os outros colegas interpretariam tal fato como uma situação de injustiça: reconhece-se o sujeito e não o seu trabalho; logo, desconhece-se o seu sofrimento e o seu mérito, o que poria em risco de destruição toda a economia da relação sofrimento-prazer.

Confrontando esse processo de constituição de identidade proposto por Dejours (1993) com algumas proposições de Habermas $(1989 ; 1987 ; 1983)$, podemos observar semelhanças e diferenças nas compreensões do processo de desenvolvimento do Eu. Tal cotejamento, no nosso entender, permite uma compreensão mais rica e profunda desse processo.

Para Habermas (1983), o desenvolvimento do Eu implica uma idéia que unifica três aspectos: cognoscitivo, lingüístico e interativo:

[...] o EU se forma em um sistema de delimitações. A subjetividade da natureza interna é delimitada com relação à objetividade de uma natureza externa perceptível, com relação à normatividade da sociedade e à intersubjetividade da linguagem [...] o EU se sabe não apenas como subjetividade, mas como uma instância que 'desde sempre' transcendeu os limites da subjetividade, realizando esta operação, ao mesmo tempo, na cognição, na linguagem e na interação: o EU pode se identificar consigo mesmo precisamente mediante a distinção entre o que é meramente subjetivo e o não-subjetivo [...] sujeito e objeto se constituem reciprocamente, e que o sujeito só pode se tornar consciente de si mesmo em relação com - na construção de - um mundo objetivo. (HABERMAS, 1983, p. 15-16). 
Para Dejours (1993), o processo de constituição da identidade, ao passar pelo julgamento e pelo reconhecimento do outro, implica a constituição do coletivo do trabalho. Não se deve confundir o coletivo com o grupo. O coletivo é mais que um grupo, pois o que o define é a construção de regras e ofícios que vão nortear as relações interpessoais e de trabalho. $\mathrm{O}$ autor tem consciência de que é muito difícil construir o coletivo. Um outro modo de nomear a construção do coletivo é a atividade deôntica: atividade de construir acordos, normas e valores que se estabilizam sob a forma de regras.

Ora, para a criação desse coletivo é necessário estabelecer relações de confiança sem as quais não haverá possibilidade de uma pessoa se submeter ao julgamento do outro, e no limite, trabalhar de forma cooperativa. O coletivo depende então de um espaço, um espaço público em que ocorra a livre circulação da palavra. Os atos de linguagem ou as ações comunicativas requerem que haja um espaço democrático para que sua expressão flua livremente.

A construção do coletivo no interior de uma gestão heterônoma e de relações de trabalho calcadas no individualismo e competitividade é significativamente dificultada no cotidiano do trabalho do professor, quer seja o do professor-pesquisador, quer seja o do professor da rede pública da Educação Básica.

Ao elaborar a teoria do agir comunicativo, Habermas (1989) propõe uma racionalidade comunicativa comprometida com a emancipação das pessoas. Assim, este autor advoga um novo conceito de razão, a razão comunicativa, assim como um novo conceito de sociedade, na qual o indivíduo não seja meio, mas fim. Eis aí um possível caminho para práticas de gestão e de docência que possam romper com os aspectos patogênicos da realidade socioinstitucional por nós abordada.

A teoria da ação comunicativa pressupõe a interação para a existência do indivíduo. Assim, a identidade que o eu experimenta é influenciada pela identidade outorgada pelo outro a esse eu.

Habermas (1983, p.22) nos ensina que ninguém poderia "edificar sua própria identidade" de forma independente das "identificações que os outros fazem dele", pois "o fundamento para a afirmação da própria identidade não é a auto-identificação tout court, mas a auto-identificação intersubjetivamente reconhecida".

Vale lembrar que, para Berger e Luckmann (1991), os papéis representam a ordem institucional, ou seja, o papel seria uma atividade padronizada previamente pela identidade coletiva, que não depende da vontade individual e que surge como imagens preestabelecidas, rotulações que aderem à identidade individual, em uma tentativa de manutenção de crenças sociais que garantam certa continuidade e cognoscibilidade à identidade coletiva.

Para Habermas (1983), o reconhecimento dialético e dialógico dos membros do grupo requer relações Eu-Tu-Nós. E, fazendo certa reserva à expressão "identidade coletiva", assim a conceitua:

[...] a identidade coletiva regula a participação dos indivíduos na sociedade (ou a sua exclusão da mesma). Sob esse aspecto, subsiste uma relação complementar entre identidade do Eu e de grupo, já que a unidade da pessoa se forma através das relações com as pessoas do mesmo grupo; e o desenvolvimento da identidade se caracteriza [...] pelo fato de que é dissolvida a identificação inicialmente realizada com grupos concretos e menos complexos (família), identidade que é depois subordinada à que se processa com unidades mais amplas e mais abstratas (cidade, Estado). (HABERMAS, 1983, p.26). 
Assim, temos uma identidade que pode ir se modificando ao longo de uma história de vida, de acordo com sua inter-relação com o meio social. Porém, quanto mais a conduta for padronizada, tanto mais será previsível e controlável. Em decorrência disso, existe uma expectativa geral de que o indivíduo deva agir mediante suas predicações, pois enquanto estiver amarrado a papéis estratificados e às normas já existentes, sua identidade estará em nível convencional.

A identidade coletiva, nesse sentido, difere-se da dinâmica dos agrupamentos que obedecem a normas e prescrições que lhes são exteriores, o quê de certa forma ocorre na organização e prática da atividade de docência nas quais a autonomia é dificultada senão impedida.

Ciampa (1994, p.140) define identidade-mito no momento em que o sujeito não consegue atingir a condição de "ser-para-si" mediante a não-superação de contradições no sentido dialético do termo. Em nosso entender, há forte semelhança entre o que Habermas (1983) chama de identidade do Eu e aquilo que Ciampa (1994) denomina de condição de "ser-para-si". De acordo com o filósofo alemão:

[...] a identidade de papel é substituída pela identidade do Eu, na exata medida em que o Eu generaliza a capacidade de superar uma velha identidade e aprende a resolver as crises de identidade reconquistando a nível mais alto o equilíbrio perdido entre si e a realidade social modificada. Pode dizer "Eu" de si mesma". (HABERMAS, 1983, p.25).

Na abordagem de Ciampa (1994, p.146) a questão identitária do "ser-para-si" é a busca da autonomização, sem a ingenuidade da inexistência de determinações exógenas na procura da "unidade da subjetividade e da objetividade, que faz do agir uma atividade finalizadora relacionando desejo e finalidade, pela prática transformadora de si e do mundo".

Aliás, esse autor nos ensina que identidade é metamorfose, ou seja, está em constante transformação. O que nos remete à idéia de Habermas (1983) de que a identidade em nível pós-convencional seria aquela em que o desenvolvimento da consciência moral supere o estágio convencional, rompendo os limites da identidade de papel, à medida que adquire a capacidade de julgar, definindo princípios e valores morais, cuja validade independe de autoridade exterior.

Dessa forma, a identidade vai sendo constituída mediante reiteradas identificações do próprio indivíduo em relação a si mesmo e ao meio social.

Goffman (1963) define a identidade social e a identidade pessoal de maneira em que a primeira consiste nos papéis que o indivíduo desempenha, suas representações no cenário em que se apresenta, enquanto a segunda é o que torna a pessoa única, com suas características subjetivas, intrínsecas. Na construção da identidade pessoal de um indivíduo são usados aspectos da identidade social:

Normas relativas à identidade pessoal, entretanto, pertencem não a esferas de combinações permissíveis de fatos sociais, mas ao tipo de controle de informação que o indivíduo pode exercer com propriedade. Para uma pessoa, ter tido o que se chama de um passado sombrio é uma questão relativa à sua identidade social; a maneira pela qual ele manipula a informação sobre esse passado é uma questão de identificação pessoal. (GOFFMAN, 1963, p.74). 
Parece-nos, portanto, que é difícil dissociar a identidade pessoal da identidade social, uma vez que ambas fazem parte da mesma pessoa. Identidade é unidade entre objetividade e subjetividade, como nos ensina Ciampa $(1994 ; 1992)$ e é nessa unidade que se dá a metamorfose, transformação constante. Na articulação entre o conceito de identidade-metamorfose e identidade-mito tentaremos levar à compreensão da participação da dimensão subjetiva na interpretação do mundo. Assim, por meio do pensamento habermasiano, que categoriza o agir instrumental e o agir comunicativo, tendemos a interpretar os fatos sociais como se fossem fenômenos naturais. Tal atitude nos afasta de nosso papel de construtores da realidade e exclui o caráter histórico de nosso existir.

Por outro lado, o agir comunicativo, carregado de historicidade, nos conduz à reflexão sobre os papéis que interpretamos e nos proporciona uma certa escolha no que concerne ao que "merece ser vivido".

Apesar das condições materiais e objetivas desfavoráveis ao exercício da docência de forma digna, é possível, no nosso entender, constituirmos uma identidade coletiva emancipatória. Não que isto seja fácil, como se deduz da simples leitura deste artigo. Mas é possível recorrermos à idéia de utopia em seu sentido clássico, qual seja, daquilo que poderá acontecer. Isto equivale a dizer que compete a nós pesquisadores e docentes resgatarmos um papel bem mais dignificado do que este que vem sendo outorgado a nós. Devemos fazer nossa própria história, mesmo porque esta "lição de casa" ninguém poderá fazer por nós. A criação do espaço da palavra e da discussão sobre o trabalho em nosso cotidiano, tal como nos aponta Dejours (1994), é condição essencial para tal.

As contradições presentes no cotidiano das instituições escolares e da docência envolvem configurações identitárias e intersubjetivas também contraditórias. Na condição de cuidador, o professor tem pouca aptidão para ser cuidado. Mergulha na sua atividade de trabalho (intensa; precarizada) e, sob certo pedestal, tende a não assumir e/ou perceber sua fragilidade. Habituou-se a "dar aulas" e não exatamente a ministrar suas preleções. O Brasil talvez seja o único país no mundo no qual enfaticamente se usa tal expressão. Mais do que isso, não raro, ainda se ouvem expressões que traduzem muito bem o imaginário do brasileiro médio em relação à Educação: "mestre, além de dar aulas, você também trabalha?". E assim segue o professor em sua jornada, "dando aulas" e, quando menos espera, se vê exaurido e, em alguns casos, como os do burnout, com sintomas de despersonalização, o que significa dizer que, nestes casos, age como um "ator sincero", que acredita no próprio personagem ou identidade-mito que assume.

Se a nossa identidade depende da alteridade, qual seja, do olhar do outro, de como ele nos vê, e de como se expressam em relação a nós, a contradição fica evidente na assunção de uma identidade que oscila, tal como um pêndulo, entre os papéis sacerdotal e profissional. "Quem somos nós?" é uma indagação recorrente que o professor faz a si em função de um imaginário abusivo, colonial e retrógado. Este imaginário possui verdadeira aversão, para não dizer desprezo, pela cultura, pela formação humanística e por qualquer coisa ou alguém que venha representá-las. No nosso entender, ainda não há um avanço suficientemente forte da visão iluminista. Perdura na cultura da sociedade brasileira o imaginário do senhor de engenho, dono de corpo e alma de seus escravos e que, portanto, tudo comprava e, em igual proporção, desprezava o que não era passível de ser comprado, a saber: cultura, educação, ética etc.

Tais aspectos podem ser relacionados à figura do diretor egocrata e aos sentimentos ambivalentes dos professores, que transitam da impotência à onipotência, do pessimismo ao idealismo, da resistência ao conformismo. 
Consideramos que a identidade, predominantemente expropriada ou ameaçada (VIEIRA, 2004) não sucumbe, porém, aos ditames da heteronomia, sendo presente, ainda que de forma frágil, a dimensão utópica de um fazer. Ou seja, existe um pêndulo em movimento e uma dimensão histórica que jamais será totalmente regulada, controlada ou subsumida à sociabilidade produtiva, ainda que esta se imponha com muita força e frequência. Não obstante, podemos afirmar que a identidade, que se relaciona às demandas autônomas e heterônomas, de modo geral, tende a ser engolfada por conflitos que inevitavelmente se articulam às realidades socioinstitucional, cultural e organizacional que, dentro das limitações deste artigo, foram pos nós tratadas.

\section{Considerações finais}

Conforme argumenta Heloani (2003) as novas formas de gestão e organização do trabalho reproduzem a racionalidade instrumental taylorista-fordista, de modo que a (pseudo)participação e a (pseudo)democracia se constituem como formas de manipulação da subjetividade que se fazem presentes no mundo do trabalho de modo geral, assim como, de modo particular, na universidade "quase mercantilizada" (SGUISSARDI \& SILVA JÚNIOR, 2009) e nas práticas e políticas educacionais da Educação Básica, que estão a reboque da configuração do Estado-gestor e da ideologia produtivista daquela.

Indivíduos e grupos são induzidos a se sentirem participantes de uma gestão meramente heterônoma. São moldados a serem produtivos e empreendedores e tendem a se aprisionar nas "armadilhas da instituição estratégica" (ENRIQUEZ, 1997), redundando em configurações subjetivas narcísicas e/ou auto-enaltecidas (professor-pesquisador) e encarnadoras do arquétipo do órfão (professor da Educação Básica).

A sociabilidade produtiva e os valores mercantis são mediadores da praxis educacional e laboral, ainda que o devir histórico possa sempre nos surpreender. Ainda que as reflexões do presente artigo não sejam promissoras, compreendemos ser necessário não nos entregarmos às adversidades socioinstitucionais e organizacionais e manter viva a incessante, difícil e complexa luta do sujeito histórico e ontológico (SILVA, 2008) pelo reconhecimento no trabalho (HONNETH, 2003). Na base econômica-Estatal da atual configuração histórica (mercantil) há uma forte tendência de negação do sujeito (instituinte) e de sua identidade, mas tal não nos deve cegar em relação à subsunção contraditória da organização escolar e do sujeito coletivo ao político e ao institucional (SILVA JÚNIOR \& FERRETTI, 2004). As tendências de consolidação da gestão educacional heterônoma na Educação Superior e na Educação Básica não são nada desprezíveis, mas se faz necessário aprofundar as pesquisas e nuances presentes na educação e no trabalho e assim se buscar fortalecer, senão construir, formas de questionamento e de resistência que vem sendo cotidianamente debeladas.

Com base nos dados das pesquisas analisados neste artigo (SGUISSARDI \& SILVA JÚNIOR, 2009; FORTUNA, 2000) concluímos que na atual configuração da realidade educacional e laboral prevalecem os prejuízos à vida sociofamiliar e à saúde do professor, sendo estes intimamente relacionados aos aspectos socioinstitucionais abordados, como gestão educacional heterônoma e a intensificação e precarização do trabalho, assim como aos psicossociais, tais como o não-reconhecimento no trabalho (professores da Educação Básica), o "reconhecimento" contraditoriamente condicionado aos interesses heterônomos e ao desgaste (professor-pesquisador), os conflitos identitários e a competitividade nas relações sociais e de trabalho. 


\section{Bibliografia:}

BERGER, Peter; LUCKMANN, Thommas. A construção social da realidade. Petrópolis, RJ: Vozes, 1991.

CIAMPA, Antonio da Costa. A estória de Severino e a história de Severina. São Paulo: Brasiliense, 1994. Identidade. In: LANE, S., CODO, W (orgs.). Psicologia Social: o homem em movimento. São Paulo: Brasiliense, 1992.

CHESNAIS, François. A mundialização do capital. São Paulo: Xamã, 1996.

CODO. Wanderley. Educação: carinho e trabalho. 3.ed. Petróplis: Vozes, 1999.

CORRÊA, Maria Laetitia; PIMENTA, Solange Maria. Teorias da administração e seus desdobramentos no âmbito escolar. In: OLIVEIRA, M. A. M. (org.). Gestão educacional: novos olhares, novas abordagens. Petrópolis, RJ: Vozes, p.22-39, 2005.

DEJOURS, Christophe. O fator humano, Rio de Janeiro: Editora FGV, 1997.

Psicodinâmica do trabalho. 2.ed. SP: Atlas, 1994.

Pour une clinique de la médiation entre psychanalyse et politique: la psychodynamique du travail. Paris: Bayard, 1993.

Uma Nova Visão do Sofrimento Humano nas Organizações. In: Chanlat, J. F. (org). O indivíduo na organização: dimensões esquecidas. São Paulo: Editora Atlas, v.1, 1992.

DUARTE, Newton. Educação escolar, teoria do cotidiano e a escola de Vigotski. Campinas, SP: Autores Associados, 2001.

Vigotski e o aprender a aprender: críticas às apropriações neoliberais e pósmodernas da teoria vigotskiana. Campinas, SP: Autores Associados, 2000.

ENRIQUEZ, Eugène. O indivíduo preso na armadilha da instituição estratégica. RAE, São Paulo, 37, (1), p.18-29, 1997.

ESTEVE, Jose Manuel. O mal-estar docente: a sala de aula e a saúde dos professores. Bauru: EDUSC, 1999.

FIORI, José Luís. Globalização, estados nacionais e políticas públicas. In: FIORI, J. L. (org.). Em busca do dissenso perdido: ensaios críticos sobre a festejada crise do Estado. Rio de Janeiro: Insigth Editorial, p.195-211, 1995.

FORTUNA, Maria Lucia de Abrantes. Gestão escolar e subjetividade. São Paulo/Niterói: Xamã/Intertexto, 2000.

FREUDENBERGER, Herbert J. The staff burn-out syndrome. Psychotherapy: theory, research and practice, 12, p.73-82, 1975.

Staff burn-out. Journal of Social Issues, 30, pp.159-165, 1974. 
GOFFMAN, Erving. Estigma: notas sobre a manipulação da identidade deteriorada. Rio de Janeiro: Zahar, 1963.

HABERMAS, Jürgen. Consciência moral e agir comunicativo. Rio de Janeiro: Tempo Brasileiro, 1989.

Teoria de la accion comunicativa. Versión castellana de Manuel Jimenes Redondo. Madrid: Taurus, 1987.

Para a reconstrução do materialismo histórico. São Paulo: Brasiliense, 1983.

HARVEY, David. Condição pós-moderna. SP: Loyola, 1993.

HELOANI, Roberto. Gestão e organização no capitalismo globalizado: história da manipulação psicológica no mundo do trabalho. SP: Atlas, 2003.

HONNETH, Alex. Luta por reconhecimento: a gramática moral dos conflitos sociais. São Paulo: Ed.34, 2003.

LEITE, Marcia de Paula; SOUZA, Aparecida Neri de. Condições de trabalho e suas repercussões na saúde dos professores da Educação Básica no Brasil. Campinas/São Paulo: Faculdade de Educação da Unicamp/Fundacentro, Relatório de Pesquisa, 2007.

LÜCK, Heloísa. Gestão Educacional: uma questão paradigmática. Petrópolis, RJ: Vozes, Série Cadernos de Gestão, v.1, 2007.

MARX, Karl. O capital: crítica da economia política. Rio de Janeiro: Civilização Brasileira, livro 1, v.2, 1971.

RAMOS, Marise Nogueira. Pedagogia das competências: autonomia ou adaptação? São Paulo: Cortez, 2001.

SGUISSARDI, Valdemar; SILVA JÚNIOR, João dos Reis. O trabalho intensificado na Federais: pós-graduação e produtivismo acadêmico. São Paulo: Xamã, 2009 (no prelo).

SILVA, Eduardo Pinto e. As concepções de subjetividade em Gramsci e Lukács e a praxis educacional. Belo Horizonte, Trabalho \& Educação, v.2, n.17, 2008.

SILVA JÚNIOR, João dos Reis. Pragmatismo e populismo na Educação Superior: nos governos Lula e FHC. São Paulo: Xamã, 2005.

SILVA JÚNIOR, João dos Reis; FERRETTI, Celso João. O institucional, a organização e a cultura da escola. São Paulo: Xamã, 2004.

SILVA JÙNIOR, João dos Reis; GONZÁLEZ, Jorge Luis Cammarano. Reformas educacionais, competências e prática social. Belo Horizonte, Trabalho \& Educação, n.9, jul.dez., 2001. 
SILVA JÚNIOR, João dos Reis; SILVA, Eduardo Pinto e. Carreira docente diante da atual configuração da pós-graduação: pragmatismo, intensificação e precarização do trabalho do professor. In: MANCEBO, D; SILVA JÙNIOR, J. dos R.; OLIVEIRA, J. F. de. Reformas e políticas: educação superior e pós-graduação no Brasil. São Paulo: Xamã, cap.8, p.189$222,2008$.

TEIXEIRA, Benedito Juberto. Influência dos estereótipos nos julgamentos do selecionador de pessoal. São Paulo: FGV/SP, 1994 (Dissertação de Mestrado).

VIEIRA, Juçara Dutra. Identidade expropriada: retrato do educador brasileiro. 2.ed. Brasília: CNTE, 2004.

\footnotetext{
i Professor Adjunto do Departamento de Educação e do Programa de Pós-Graduação em Educação (PPGE) da UFSCar, linha de pesquisa Educação e Trabalho. Mestre e Doutor em Educação pela UNICAMP. E-mail: dups@ig.com.br

ii Professor Titular da Faculdade de Educação e da Pós-Graduação em Educação da UNICAMP, linha de pesquisa Gestão, Saúde e Subjetividade. Professor da FGV-SP. Mestre em Administração pela FGV-SP e Doutor em Psicologia Social pela PUC-SP. E-mail: roberto.heloani@fgv.br

iii Em 2008, sob a liderança do Prof. Dr. José Roberto Heloani (UNICAMP), foi constituída, no interior do Grupo de Pesquisa do LAGE-UNICAMP, a linha de pesquisa Gestão, Saúde e Subjetividade. O GEPEFH, constituído em 2008 na UFSCar, tem como líder o Prof. Dr. João dos Reis Silva Júnior (UFSCar) e como vice-líder o Prof. Dr. Eduardo Pinto e Silva (UFSCar).

iv O termo tricherie não possui a conotação pejorativa que no linguajar comum é geralmente atribuída aos termos "trapaça" ou "gambiarra". Ele se refere às renormatizações do trabalho prescrito que flexibilizam o modo operatório da tarefa, tornando-a mais eficaz e condizente à subjetividade do trabalhador.
}

Artigo recebido em: 16/03/2009

Aprovado para publicação em: 15/05/2009 